\title{
QUANTIFICAÇÃO DO EFEITO DO CRESTAMENTO BACTERIANO COMUM NA EFICIÊNCIA FOTOSSINTÉTICA E NA PRODUÇÃO DO FEIJOEIRO
}

\author{
CECILIA G. DÍAZ, RENATO B. BASSANEZI, CLÁUDIA V. GODOY, DANIELA B. LOPES \& \\ ARMANDO BERGAMIN FILHO
}

Departamento de Entomologia, Fitopatologia e Zoologia Agrícola, Escola Superior de Agricultura "Luiz de Queiroz", Universidade de São Paulo, Cx. Postal 9, CEP 13418-900, Piracicaba, SP, fax: (019) 434 4839, e-mail:

abergami@carpa.ciagri.usp.br

(Aceito para publicação em 13/09/2000)

Autor para correspondência: Armando Bergamin Filho

DÍAZ, C.G., BASSANEZI, R.B., GODOY, C.V., LOPES, D.B. \& BERGAMIN FILHO, A. Quantificação do efeito do crestamento bacteriano comum na eficiência fotossintética e na produção do feijoeiro. Fitopatologia Brasileira 26:71-76. 2001.

\section{RESUMO}

O efeito do agente causal do crestamento bacteriano comum na eficiência fotossintética e na produção do feijoeiro (Phaseolus vulgaris) foi quantificado. Dois experimentos de campo foram conduzidos durante a safra das águas de 1997, em Piracicaba-SP, com duas cultivares, IAC-Carioca e Rosinha. Diferentes níveis de severidade foram obtidos variando-se o número de inoculações com o patógeno. A severidade da doença, avaliada com auxílio de escala diagramática, não apresentou relação linear significativa $(P>0,01) \mathrm{com}$ a produção, enquanto a duração da área foliar sadia $(H A D)$ relacionou-se linearmente de forma significativa $(P \leq 0,01) \mathrm{com}$ a produção nos dois experimentos $\left(R^{2}\right.$ entre 0,66 e 0,78$)$. A fotossíntese foi relacionada com área foliar doente por meio da equação $P_{\mathrm{x}} / P_{0}=(1-x)^{\beta}$, onde $P_{\mathrm{x}}$ é a fotossíntese líquiuda da folha com severidade $x, P_{0}$ é a fotossíntese líquida média das folhas sadias, $x$ é a severidade da doença e $\beta$ expressa a relação entre lesão virtual e lesão visual. Os valores de $\beta$, determinados por

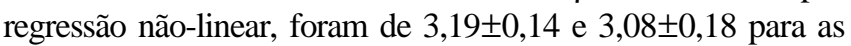
cultivares IAC-Carioca e Rosinha, respectivamente. A incorporação de $\beta$ ao cálculo de $H A D$, de modo geral, não melhorou significativamente o ajuste dos dados.

Palavras-chave: Phaseolus vulgaris, Xanthomonas axonopodis pv.phaseoli, lesão virtual, lesão visual, eficiência fotossintética, avaliação de danos.

\section{ABSTRACT \\ Effect of common bacterial blight in the photosynthetic efficiency and in the yield of common bean}

The effect of common bacterial blight on photosynthetic efficiency and on common bean (Phaseolus vulgaris) yield was quantified. Two experiments were carried out during the wet season of 1997 at Piracicaba-SP using two cultivars, IAC-Carioca and Rosinha. Different levels of severity were obtained by varying the number of inoculations with the pathogen. Disease severity, assessed with a diagrammatic scale, did not show a significant linear relationship $(P>0.01)$ with yield, while the healthy leaf area duration $(H A D)$ was significantly $(P \leq 0.01)$ linear in relation to yield in both experiments $\left(R^{2}\right.$ between 0,66 and $0,78)$. Photosynthesis was related to diseased leaf area by the equation $P_{\mathrm{x}} / P_{0}=(1-x)^{\beta}$, where $P_{\mathrm{x}}$ is the net photosynthesis of the leaf with severity $x, P_{0}$ is the mean net photosynthesis of the healthy leaves, $x$ is the disease severity, and $\beta$ is the relation between virtual and visual lesion. The values of $\beta$, determined by non-linear regression, were $3.08 \pm 0.18$ and $3.19 \pm 0.14$ for IAC-Carioca and Rosinha, respectively. In general, the use of $\beta$ did not significantly improve the $H A D$-yield relationship.

\section{INTRODUÇÃO}

O crestamento bacteriano comum, causado por Xanthomonas axonopodis pv.phaseoli (Vauterin et al., 1995) ( $=X$. campestris pv. phaseoli), é a principal doença bacteriana da cultura do feijoeiro (Phaesolus vulgaris L.) no Brasil. Danos de $38 \%$ e $45 \%$ já foram relatados (Wallen \& Jackson, 1975; Yoshii et al, 1976). Goodwin (1992) considera que a redução da eficiência fotossintética das plantas doentes é a causa principal dos danos causados pela doença.
Waggoner \& Berger (1987), baseados nos estudos clássicos de Monteith (1972), propuseram que a produção de grãos ou matéria seca é função, em grande parte, da área verde (sadia) fotossintetizante da planta e não da área ocupada pelo patógeno (o mesmo que severidade de doença). Johnson (1987) refinou ainda mais esse conceito ao propor que a produção é função não só da área foliar sadia e da radiação absorvida por ela, mas também de sua eficiência fotossintética.

Os fitopatógenos podem afetar a eficiência fotossintética de seus hospedeiros de diversas maneiras (Johnson, 
1987; Shtienberg, 1992). Bastiaans (1991) propôs um modelo para quantificar esse efeito: $P_{\mathrm{x}} / P_{0}=(1-x)^{\beta}$, onde $P_{\mathrm{x}}$ é a fotossíntese líquida da folha com severidade $x, P_{0}^{\mathrm{x}}$ é a fotossíntese líquida média das folhas sadias, $x$ é a severidade da doença e $\beta$ expressa a relação entre lesão virtual e lesão visual. Valores de $\beta$ iguais à unidade indicam que o patógeno não afeta a eficiência fotossintética; valores de $\beta$ superiores à unidade indicam reduções na eficiência fotossintética. Bassanezi (2000) ressaltou a conveniência de incorporar a lesão virtual em modelos de danos. $O$ valor de $\beta$ característico de cada patossistema, assim, poderia funcionar como um fator de correção da severidade.

Este trabalho teve como objetivos a quantificação do parâmetro $\beta$ para as cultivares IAC-Carioca e Rosinha infetados por $X$. axonopodis pv. phaseoli e a correção dos valores de severidade obtidos com auxílio de escala diagramática, com o intuito de definir modelos de danos mais precisos para o crestamento bacteriano comum do feijoeiro.

\section{MATERIAL E MÉTODOS}

Dois experimentos de campo foram conduzidos com as cultivares de feijão IAC-Carioca e Rosinha. O primeiro foi semeado em 13/12/1996 e o segundo em 28/12/1996. Práticas culturais, como capina e irrigação, foram realizadas conforme a necessidade da cultura. Para cada cultivar, foi semeada uma área de $400 \mathrm{~m}^{2}$. Cada área continha 12 parcelas com quatro tratamentos e três repetições por cultivar. Os tratamentos foram $\mathrm{T} 1=$ sem inoculação; $\mathrm{T} 2=$ uma inoculação; T3=duas inoculações; T4= três inoculações. O delineamento experimental foi em blocos casualizados, sendo cada parcela constituída de seis sulcos de $6 \mathrm{~m}$ de comprimento, espaçados de $0,5 \mathrm{~m}$ e densidade do plantio de 12 plantas por metro linear. Utilizou-se como área útil as duas linhas centrais, nas quais foram marcadas seis plantas, duas por sulco, espaçadas de $2 \mathrm{~m}$ entre si, totalizando 36 plantas de cada cultivar para cada um dos dois experimentos. Todas as avaliações foram realizadas nas plantas marcadas.

\section{Patógeno e inoculação}

$\mathrm{O}$ isolado de $X$. axonopodis pv. phaseoli utilizado foi o Xp-CNF-15, fornecido pela EMBRAPA Arroz e Feijão de Goiânia, GO. Utilizou-se uma concentração de inóculo de $10^{8} \mathrm{ufc} / \mathrm{ml}$. A inoculação foi realizada quando as plantas apresentavam o primeiro trifólio completamente expandido (estádio V3/V4), ao final da tarde, com irrigação prévia de 30 min para garantir um microclima úmido para a multiplicação e posterior penetração da bactéria. Ferimentos foram feitos nas plantas por meio de pulverização com areia e posterior abrasão das folhas com lixa de madeira (grão médio). Após esse procedimento, aplicou-se a suspensão bacteriana por meio de pulverização com alta pressão.

\section{Avaliação do crestamento bacteriano comum}

Para quantificar o crestamento bacteriano comum, foi empregada escala diagramática de severidade. Estimou-se a severidade da doença (\%) para todas as folhas das plantas marcadas, a intervalos semanais. Com os dados de severidade ao longo do tempo calculou-se a área sob a curva de progresso da doença $(A U D P C)$ pelo método de integração trapezoidal.

\section{Avaliação do hospedeiro e determinação da função de produção}

A estimativa da área foliar $\left(L A, \mathrm{~cm}^{2}\right)$ foi realizada por meio da equação $A F=2,137094 *\left((L F C)^{1,96418}\right)-2,701269$ (Iamauti, 1995), onde $A F$ é a área foliar e $L F C$ é a largura maior do folíolo central. As avaliações foram feitas a intervalos de sete a nove dias, totalizando seis a sete avaliações, dependendo da cultivar. Com base no estande final da parcela útil e na área foliar da planta, calculou-se o índice de área foliar $(L A I)$ de cada planta, para cada data de avaliação. A duração da área foliar sadia $(H A D)$ foi calculada segundo a equação de Waggoner \& Berger (1987)

$H A D=\sum_{i=1}^{n-1}\left\{\left[L A I_{i}\left(1-x_{i}\right)+L A I_{i+1}\left(1-x_{i+1}\right)\right] / 2\right\}\left(t_{i+1}-t_{i}\right)$

onde $L A I_{i}$ é o índice de área foliar no tempo $t_{i}$ e $x_{i}$ representa o tecido doente, considerando a lesão visual no tempo $t_{i}$. $\mathrm{O}$ valor de $\beta$ foi incorporado ao cálculo de $H A D$ substituindo-se $\left(1-x_{i}\right)$ por $Y_{i}=1-\left(1-x_{i}\right)^{\beta}$, onde $Y_{i}$ é a lesão virtual no tempo $t_{i}$ e $x_{i}$ é a lesão visual no tempo $t_{i}$ (Bassanezi, 2000).

\section{Determinação de $\beta$}

Com o início do aparecimento dos sintomas, foram iniciadas as avaliações, sempre no mesmo horário, para a determinação da relação entre severidade da doença e taxa fotossintética, utilizando-se o equipamento portátil de avaliação de fotossíntese LI-6400 (LICOR, USA). Foram escolhidas 85 a 90 folhas de mesmo tamanho e idade fisiológica, com diferentes níveis de severidade da doença. Após cada avaliação, as folhas foram destacadas e a região do folíolo central, que estava dentro da câmara de trocas gasosas, foi marcada com auxílio de uma moldura. A área lesionada foi desenhada em plástico transparente e a severidade da doença nessa região foi estimada com auxílio de medidor de área foliar LI-3000 (LICOR, USA). Considerou-se como lesionada qualquer área da folha com sintomas de crestamento bacteriano comum, incluindo o halo clorótico ao redor das lesões necróticas. Os valores de $\beta$ foram estimados pela equação $P_{\mathrm{x}} / P_{0}=(1-x)^{\beta}$ (Bastiaans, 1991) por regressão não-linear, utilizando-se o programa STATISTICA (StatSoft, Tulsa, EUA). O teste $t$ (Campbell \& Madden, 1990) foi realizado para verificar se os valores de $\beta$ diferiam da unidade.

\section{RESULTADOS E DISCUSSÃO}

As condições ambientais (temperatura da folha, concentração de $\mathrm{CO}_{2}$ do ar, umidade relativa do ar e intensidade da radiação fotossinteticamente ativa) de ambos os experimentos, assim como os valores máximos e médios de $A U D P C$ e produção, encontram-se na Tabela 1 . 
Quantificação do efeito do crestamento bacteriano comum na eficiência fotossintética...

TABELA 1 - Condições ambientais durante as avaliações da taxa fotossintética (temperatura da folha, concentração de $\mathrm{CO}_{2}$ do ar, umidade relativa do ar, PAR-radiação fotossinteticamente ativa), $A U D P C$ (com e sem $\beta$ ) e produção dos experimentos 1 e 2 (Máx.=máxima; Méd.=média \pm desvio padrão). Safra das águas de 1997, Piracicaba, São Paulo

\begin{tabular}{|c|c|c|c|c|c|c|c|c|c|c|}
\hline \multirow[t]{2}{*}{ Experimento e cultivar } & \multirow{2}{*}{$\begin{array}{c}\text { Temperatura }\left({ }^{\circ} \mathrm{C}\right) \\
\text { Méd. } \\
\end{array}$} & \multirow{2}{*}{$\begin{array}{c}\begin{array}{c}\text { Conc. de } \mathrm{CO}_{2} \\
\left(\mu \mid \mathrm{I}^{-1}\right)\end{array} \\
\text { Méd. } \\
\end{array}$} & \multirow{2}{*}{$\begin{array}{c}\begin{array}{c}\text { Umidade } \\
\text { relativa } \\
(\%)\end{array} \\
\text { Méd. } \\
\end{array}$} & \multirow{2}{*}{$\begin{array}{c}\begin{array}{c}\text { PAR } \\
\left(\mu \text { mol.m }^{-2} \cdot \mathrm{s}^{-1}\right)\end{array} \\
\text { Méd. } \\
\end{array}$} & \multicolumn{2}{|c|}{$A U D P C \operatorname{sem} \boldsymbol{\beta}$} & \multicolumn{2}{|c|}{$A U D P C \operatorname{com} \boldsymbol{\beta}$} & \multicolumn{2}{|c|}{ Produção $\left(g / m^{2}\right)$} \\
\hline & & & & & Máx. & Méd. & Máx. & Méd. & Máx. & Méd. \\
\hline $10 c \mathrm{c}$ & $39,3 \pm 3,1$ & $371 \pm 21$ & $36 \pm 6$ & $1679 \pm 250$ & 363 & $114 \pm 60$ & 807 & $303 \pm 151$ & 634 & $420 \pm 90$ \\
\hline 1 - Rosinha & $40,0 \pm 2,7$ & $357 \pm 13$ & $35 \pm 4$ & $1934 \pm 291$ & 251 & $102 \pm 53$ & 593 & $264 \pm 125$ & 552 & $209 \pm 106$ \\
\hline 2 - IAC-Carioca & $39,5 \pm 2,7$ & $384 \pm 14$ & $35 \pm 6$ & $1648 \pm 239$ & 401 & $157 \pm 82$ & 928 & $400 \pm 191$ & 408 & $278 \pm 50$ \\
\hline 2 - Rosinha & $40,1 \pm 2,0$ & $348 \pm 11$ & $57 \pm 8$ & $1868 \pm 377$ & 377 & $202 \pm 67$ & 924 & $519 \pm 162$ & 345 & $199 \pm 61$ \\
\hline
\end{tabular}

Os valores de taxa fotossintética relativa e de severidade de doença foram bem ajustados ao modelo proposto por Baastians (1991) ( $R^{2}$ de 0,62 a 0,84), não havendo qualquer tendência na distribuição dos resíduos. Os valores estimados do parâmetro $\beta \pm$ erro padrão, levando-se em conta os dois experimentos, foram de 3,19 $\pm 0,14\left(R^{2}=0,84\right)$ para a cv. IAC-Carioca e 3,08 $\pm 0,18\left(R^{2}=0,71\right)$ para a cv. Rosinha (Figura 1). Ambos foram maiores que $1(P<0,001)$, indicando que o patógeno reduz a taxa fotossintética nos tecidos verdes remanescentes das folhas infetadas, o que está de acordo com Goodwin (1992), que relatou $\beta=2,68 \pm 0,22\left(R^{2}=0,59\right)$ para o mesmo patossistema (cv. Sprint).

Bastiaans (1991) relatou $\beta=3,0$ para o patossistema arroz-Magnaporthe grisea. Outros patossistemas, segundo o mesmo autor, apresentam valores maiores (trigo-Erysiphe graminis, $\beta=8,7$ ) e menores (trigo-Puccinia recondita, $\beta=1,2$ ) para esse parâmetro. No caso específico de outras doenças do feijoeiro, Bassanezi (2000) determinou valores de $\beta$ de 2,17, 3,81 e 7,97 para ferrugem, mancha-angular e antracnose, respectivamente. Lopes (1999) observou valores de $\beta$ semelhantes àqueles encontrados por Bassanezi (2000) para ferrugem e antracnose.

Não houve diferença significativa para os valores de $\beta$ entre as cultivares IAC-Carioca e Rosinha pelo teste $t$ a $P=0,05$. Bastiaans \& Roumen (1993) também não detectaram diferença entre valores de $\beta$ para três cultivares de arroz infetadas por M. grisea. Bassanezi (2000), trabalhando com três doenças do feijoeiro (ferrugem, antracnose e manchaangular), duas cultivares (Carioca e Rosinha), diferentes estádios de desenvolvimento do hospedeiro e diferentes temperaturas, só detectou diferenças significativas no valor de $\beta$ para as diferentes doenças. Lopes (1999) observou que o estresse nutricional teve pouco impacto sobre os valores de $\beta$ para folhas de feijoeiro com ferrugem e antracnose. O parâmetro $\beta$, portanto, parece ser bastante robusto, característico de cada patossistema, e não-influenciável por variações de ambiente, estádio de desenvolvimento ou condição nutricional do hospedeiro. Fatores de estresses abióticos que poderiam afetar a fotossíntese das folhas também afetam, simultaneamente e do mesmo modo, o desenvolvimento da doença e o aparecimento de sintomas (Lopes, 1999; Bassanezi, 2000).
Produção e $A U D P C$ não apresentaram correlação significativa entre si, fato já demonstrado para diversas doenças do feijoeiro (Iamauti, 1995; Nunes \& Bergamin Filho, 1996; Bergamin Filho et al., 1997; Carneiro et al., 1997). A incorporação de $\beta$ nas estimativas de severidade de doença, apesar de aumentar consideravelmente a área considerada doente $(A U D P C$ com $\beta>A U D P C$ sem $\beta$, Tabela 1$)$, não melhorou a correlação entre quantidade de doença e produção (dados não-apresentados). Um dos motivos para a nãocorrelação entre severidade e produção deve ser a característica de crescimento indeterminado das cultivares de feijoeiro empregadas neste trabalho (Bergamin Filho et al., 1997). Para hospedeiros de crescimento determinado, geralmente há boa correlação entre severidade de doença e produção (Lopes et al., 1994; Bergamin Filho et al., 1995).

Produção e $H A D$ foram relacionadas entre si através de regressões lineares altamente significativas $(P<0,01)$ e com distribuição dos resíduos sem tendências, tanto para cv. IACCarioca quanto para cv. Rosinha (Figura 2), com altos coeficientes de determinação $(0,78$ e 0,76 , para cv. IACCarioca, e 0,76 e 0,66, para cv. Rosinha nos experimentos 1 e 2, respectivamente). Esse fato já havia sido relatado para outras doenças do feijoeiro (Iamauti, 1995; Nunes \& Bergamin Filho, 1996; Bergamin Filho et al., 1997; Carneiro et al., 1997; Silva et al., 1998) e é de ocorrência comum para diversos patossistemas (Lopes et al., 1994; Bergamin Filho et al., 1995).

A incorporação de $\beta$ ao cálculo de $H A D$, ao contrário do esperado, não contribuiu significativamente para melhorar o ajuste do modelo aos dados (Figura 2), produzindo coeficientes de determinação praticamente idênticos $(0,78 v s$. 0,78 e 0,76 vs. 0,75, para cv. IAC-Carioca e 0,76 vs. 0,76 e 0,66 vs. 0,68, para cv. Rosinha sem e com incorporação do $\beta$ nos experimentos 1 e 2 , respectivamente). Também para os coeficientes angulares das retas, a incorporação de $\beta$ não alterou significativamente os resultados (Figura 2): 1,39 e 1,38 , sem e com $\beta$, para cv. IAC-Carioca no experimento 1 ; 0,95 e 0,95 , sem e com $\beta$, para cv. IAC-Carioca no experimento $2 ; 2,63$ e 2,53 , sem e com $\beta$, para cv. Rosinha no experimento $1 ; 1,62$ e 1,75, sem e com $\beta$, para cv. Rosinha no experimento 2 . 
IAC-CARIOCA
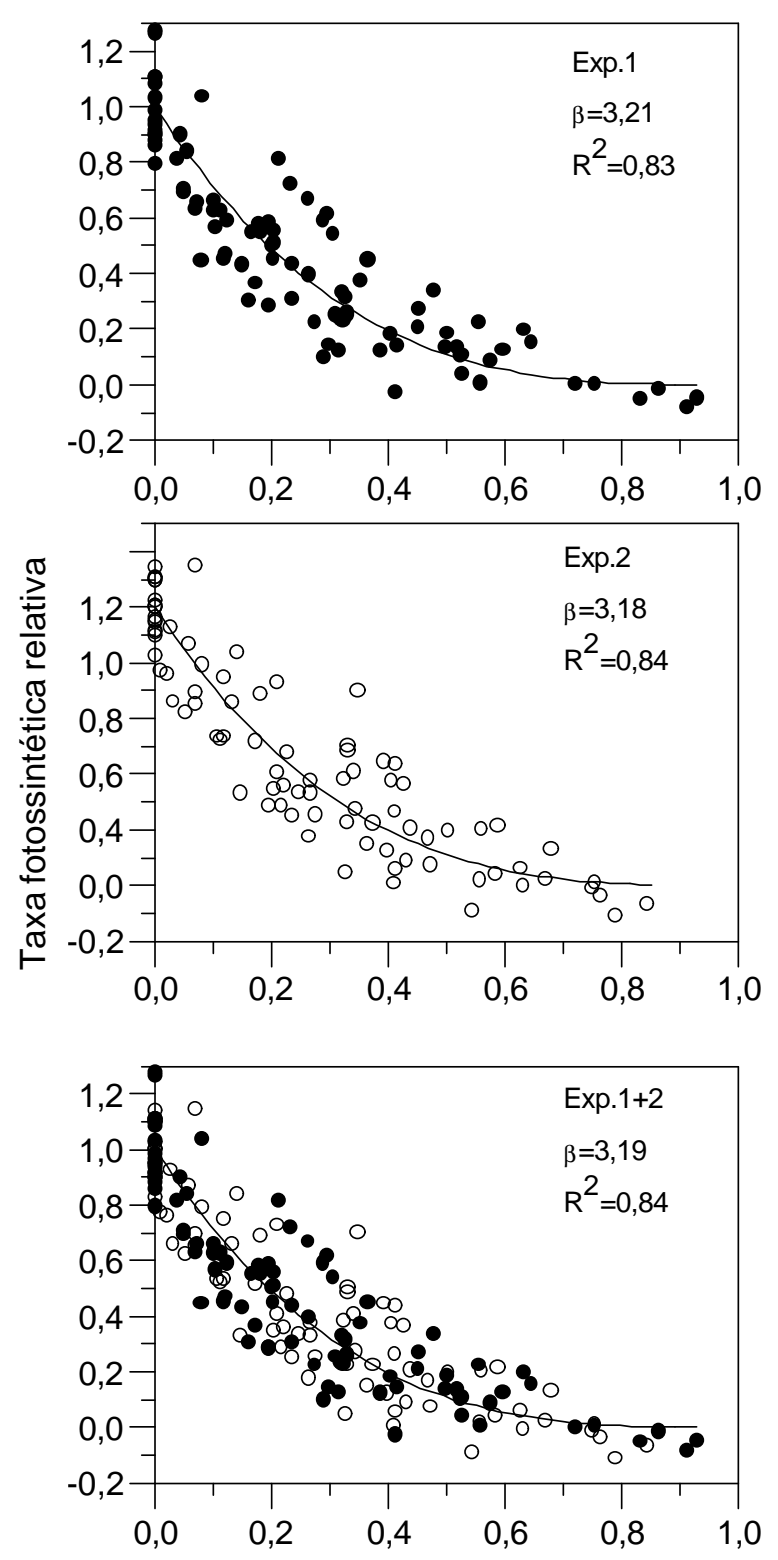

ROSINHA
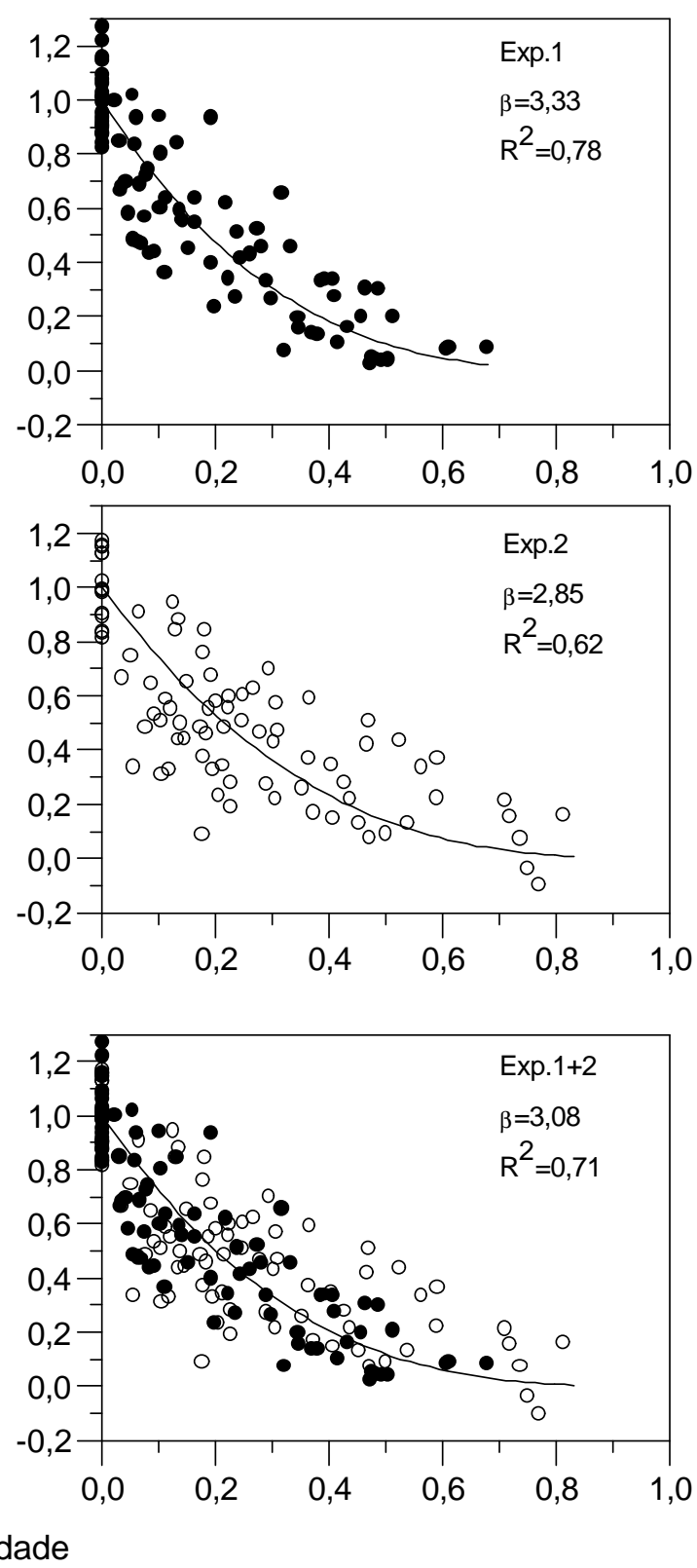

FIG. 1 - Relação entre a taxa fotossintética líquida relativa e a severidade do crestamento bacteriano comum nas cultivares de feijoeiro IAC-Carioca e Rosinha, em dois experimentos (Exp.1 e Exp.2) e no conjunto dos dois experimentos $(\operatorname{Exp} 1+2)$. $O$ parâmetro $\beta$ (relação entre lesão virtual e lesão visual) foi calculado por meio da equação $P_{x} / P_{0}=(1-x)^{\beta}$, onde $P_{x}$ é a fotossíntese líquida da folha com severidade de doença $x, P_{0}$ é a fotossíntese líquida média das folhas sadias $\left(P_{0}, \mathrm{em} \mu \mathrm{mol} \mathrm{CO} \mathrm{Cm}^{-2} \mathrm{~s}^{-1}\right.$, é igual a 19,8 e 20,8, para cv. IAC-Carioca, e 21,8 e 22,2, para cv. Rosinha, nos experimentos 1 e 2 respectivamente).

Resultados semelhantes a esses foram relatados recentemente por Bassanezi (2000) para ferrugem, manchaangular e antracnose do feijoeiro. Somente quando a severidade da doença era elevada desde poucos dias após o plantio até a colheita é que a incorporação de $\beta$ no cálculo do $H A D$ melhorou consideravelmente os valores de $R^{2}$. O trabalho de Bassanezi (2000) e os dados apresentados neste trabalho são os primeiros publicados na literatura que incorporam o parâmetro $\beta$ no cálculo de $H A D$. Estudos adicionais são necessários antes que se possa construir uma moldura conceitual que explique os resultados encontrados. $\mathrm{O}$ aumento da eficiência fotossintética das folhas sadias de plantas doentes, não-quantificado nesses estudos, pode ser área promissora para pesquisa adicional (Stangarlin, 1999). 
Quantificação do efeito do crestamento bacteriano comum na eficiência fotossintética...

IAC-CARIOCA

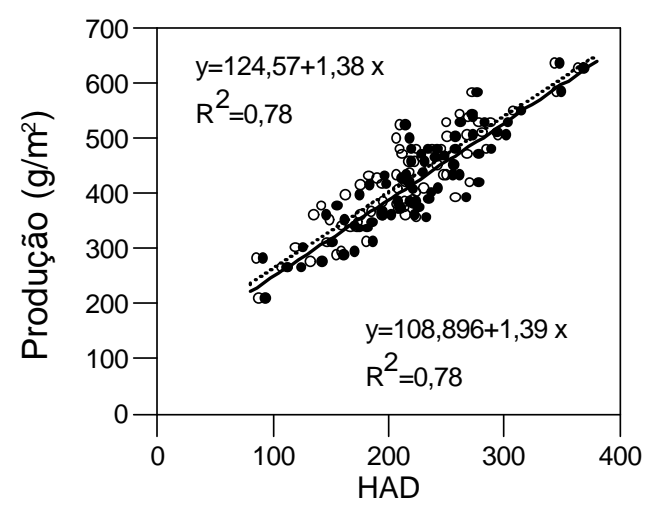

ROSINHA

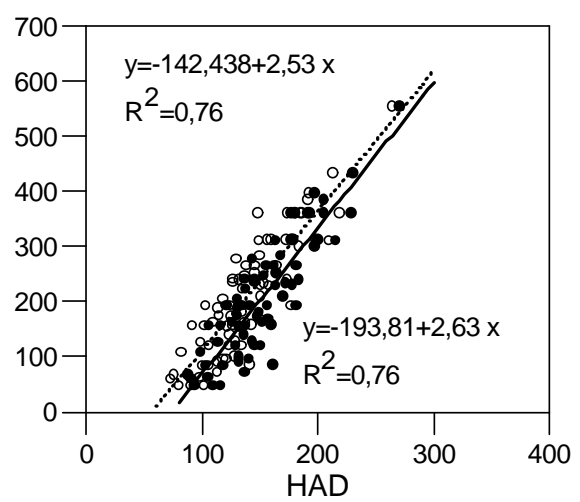

Experimento 1
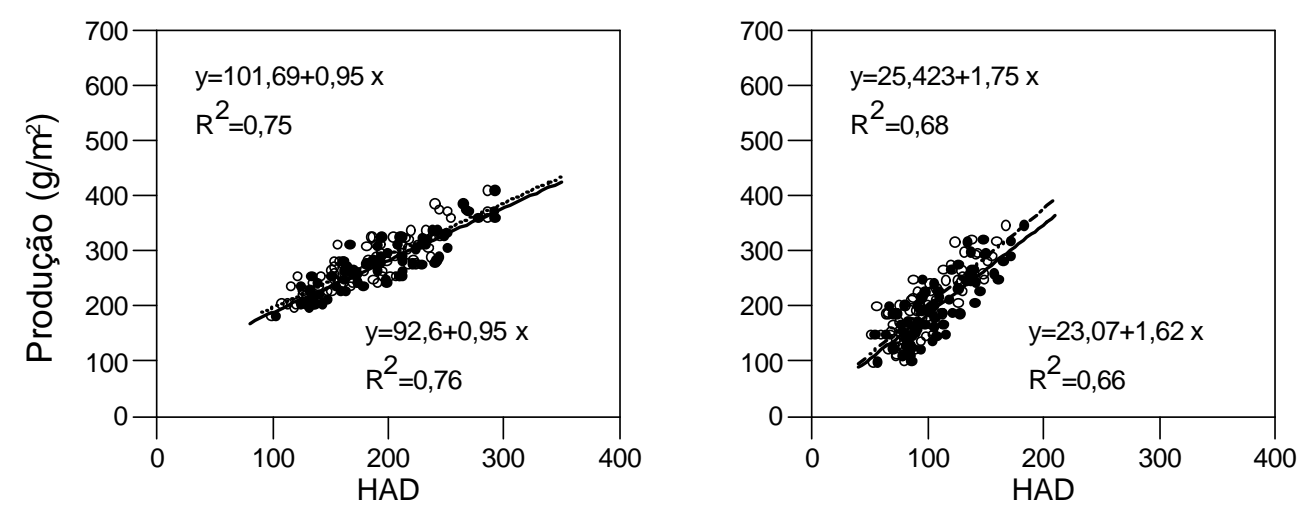

Experimento 2

FIG. 2 - Relação entre $H A D$ (com e sem $\beta$ ) e produção $\left(\mathrm{g} / \mathrm{m}^{2}\right)$ para as cultivares IAC-Carioca e Rosinha de feijoeiro (Phaseolus vulgaris). Círculos cheios indicam valores de HAD sem o parâmetro $\beta$. Círculos vazios indicam valores de $H A D$ com o parâmetro $\beta$. Linhas contínuas representam retas de regressão entre os círculos cheios e produção (sem $\beta$ ); a equação da reta e seu coeficiente de determinação aparecem na parte inferior das figuras. Linhas tracejadas representam a reta de regressão entre os círculos vazios e produção (com $\beta$ ); a equação da reta e seu coeficiente de determinação aparecem na parte superior das figuras.

Eficiência maior de folhas sadias de plantas doentes pode anular em parte o efeito da incorporação de $\beta$ no cálculo de $H A D$, explicando, assim, os resultados aqui relatados.

\section{REFERÊNCIAS BIBLIOGRÁFICAS}

BASSANEZI, R.B. Efeito de doenças foliares na eficiência fotossintética do feijoeiro (Phaseolus vulgaris L.) como contribuição na avaliação de danos (Tese de Doutorado). Piracicaba. Universidade de São Paulo. 2000.

BASTIAANS, L. Ratio between virtual and visual lesion size as a measure to describe reduction in leaf photosynthesis of rice due to leaf blast. Phytopathology 81:611-615. 1991.

BASTIAANS, L. \& ROUMEN, E.C. Effects on leaf photosynthetic rate by leaf blast for rice cultivars with different types and levels of resistance. Euphytica 66: 81-87. 1993.

BERGAMIN FILHO, A., CARNEIRO, S.M.T.P.G., GODOY,
C.V., AMORIM, L., BERGER, R. \& HAU, B. Angular leaf spot of Phaseolus bean: relationships between disease, healthy leaf area, and yield. Phytopathology 87: 506-515, 1997.

BERGAMIN FILHO, A., LOPES, D.B., AMORIM, L., GODOY, C.V. \& BERGER, R.D. Avaliação de danos causados por doenças de plantas. Revisão Anual de Patologia de Plantas 3:133-184. 1995.

CAMPBELL, C.L. \& MADDEN, L.V. Introduction to plant disease epidemiology. New York. John Wiley \& Sons. 1990.

CARNEIRO, S.M.T.P.G., AMORIM, L. \& BERGAMIN FILHO, A. Avaliação de dano provocado pela manchaangular em feijoeiro: relação entre severidade, área foliar e componentes de produção. Fitopatologia Brasileira 22: 427-431. 1997.

GOODWIN, P.H. Effects of common bacterial bligth on leaf photosynthesis of bean. Canadian Journal of Plant Pathology 14:203-206. 1992. 
IAMAUTI, M.T. Avaliação de danos causados por Uromyces appendiculatus no feijoeiro (Tese de Doutorado). Piracicaba. Universidade de São Paulo. 1995.

JOHNSON, K.B. Defoliation, disease and growth: a reply. Phytopathology 77: 1495-1497. 1987.

LOPES, D.B. Photosynthetic competence of bean leaves with rust and anthracnose (PhD Thesis). Gainesville. University of Florida. 1999.

LOPES, D.B., R.D. BERGER \& BERGAMIN FILHO, A Absorção da área foliar sadia $(H A A)$ : uma nova abordagem para a quantificação de dano e para o manejo integrado de doença. Summa Phytopathologica 20:143151.1994.

MONTEITH, J.L. Solar radiation and productivity in tropical ecosystems. Journal of Applied Ecology 9: 746-747. 1972.

NUNES, W.M.C. \& BERGAMIN FILHO, A. Avaliação dos danos causados pela antracnose (Colletotrichum lindemuthianum) do feijoeiro. Fitopatologia Brasileira 21: 436-442. 1996.

SHTIENBERG, D. Effects of foliar diseases on gas exchange processes: a comparative study. Phytopathology 82: 760-
765.1992.

SILVA, M.B., VALE, F.X.R., ZAMBOLIM, L. \& HAU, B. Efeitos da ferrugem, da antracnose e da mancha-angular na área foliar de plantas de feijoeiro em condições de campo. Fitopatologia Brasileira 23: 442-447. 1998.

STANGARLIN, J.R. Atividades de ribulose-1-5-fosfato carboxilase (Rubisco), clorofilase, $\beta-1,3$ glucanase e quitinase e conteúdo de clorofila em cultivares de feijoeiro (Phaseolus vulgaris) infetados com Uromyces appendiculatus ou Phaeoisariopsis griseola (Tese de Doutorado). Piracicaba. Universidade de São Paulo. 1999.

WAGGONER, P.E. \& BERGER, R.D. Defoliation, disease and growth. Phytopathology 77: 393-398. 1987.

WALLEN, V.R. \& JACKSON, H.R. Model for yield loss determination of bacterial blight of field beans utilizing infrared photography combined with field plot studies. Phytopathology 65: 942-948. 1975.

YOSHII, K., GALVEZ, G. E. \& ALVAREZ, G. Estimation of yield losses in beans caused by commom blight. Proceeding of the American Phytopathology Society 3:298-299.1976. 